OPEN ACCESS

Edited by: Karine Rachel Prudent Breckpot, Vrije University Brussel, Belgium

Reviewed by: Evelien Smits, University of Antwerp, Belgium Sebastian Gnat, University of Life Sciences of Lublin, Poland

*Correspondence: Xiaofeng Dai xiaofeng.dai@jiangnan.edu.cn

${ }^{\dagger}$ These authors have contributed equally to this work

Specialty section: This article was submitted to Cancer Immunity and Immunotherapy, a section of the journal Frontiers in Oncology

Received: 22 December 2021 Accepted: 31 January 2022 Published: 23 February 2022

Citation:

Dai X, Li J, Chen Y and Ostrikov K(K) (2022) When Onco-Immunotherapy Meets Cold Atmospheric Plasma: Implications on CAR-T Therapies.

Front. Oncol. 12:837995. doi: 10.3389/fonc.2022.837995

\section{When Onco-Immunotherapy Meets Cold Atmospheric Plasma: Implications on CAR-T Therapies}

\author{
Xiaofeng Dai ${ }^{1,2^{\star t}}$, Jitian $\mathrm{Li}^{3 \dagger}$, Yiming Chen ${ }^{1}$ and Kostya (Ken) Ostrikov ${ }^{4}$ \\ 1 Wuxi School of Medicine, Jiangnan University, Wuxi, China, ${ }^{2}$ CAPsoul Biotechnology Company, Ltd, Beijing, China \\ ${ }^{3}$ Henan Luoyang Orthopedic Hospital (Henan Provincial Orthopedic Hospital)/Henan Provincial Orthopedic Institute, \\ Zhengzhou, China, ${ }^{4}$ School of Chemistry and Physics and Centre for Biomedical Technologies, Queensland University of \\ Technology, Brisbane, QLD, Australia
}

T cells engineered with chimeric antigen receptors (CAR) have demonstrated its widespread efficacy as a targeted immunotherapeutic modality. Yet, concerns on its specificity, efficacy and generalization prevented it from being established into a first-line approach against cancers. By reviewing challenges limiting its clinical application, ongoing efforts trying to resolve them, and opportunities that emerging oncotherapeutic modalities may bring to temper these challenges, we conclude that careful CAR design should be done to avoid the off-tumor effect, enhance the efficacy of solid tumor treatment, improve product comparability, and resolve problems such as differential efficacies of costimulatory molecules, cytokine storm, tumor lysis syndrome, myelosuppression and severe hepatotoxicity. As a promising solution, we propose potential synergies between CAR-T therapies and cold atmospheric plasma, an emerging onco-therapeutic strategy relying on reactive species, towards improved therapeutic efficacies and enhanced safety that deserve extensive investigations.

Keywords: cold atmospheric plasma, onco-immunotherapy, chimeric antigen receptor, off-tumor effect, solid tumor

\section{INTRODUCTION}

Adoptive cell therapy (ACT) takes advantages of the immune system by transfusing back one's own genetically engineered $\mathrm{T}$ cells or cancer-cognate lymphocytes that identify and attack malignant cells or foreign invasions (1). Adjuvant chemo- or radio- therapies are conventionally applied before ACT infusion to allow infused T cells to flourish by depleting patients' endogenous immune cells $(1,2)$. Four types of immune cells are typically used to confer such clinical features, i.e., engineered peripheral blood $\mathrm{T}$ lymphocytes expressing $\mathrm{T}$ cell receptors (TCRs) or chimeric antigen receptors recognizing tumors (CARs), tumor infiltrating lymphocytes (TILs) expanded ex vivo, and T cells specific to viruses $(3,4)$ (Figure $\mathbf{1}$ ).

The efficacies of most ACT strategies are limited to certain types of diseases. While infusion of ex vivo-expanded TILs has demonstrated its efficacy in curing refractory metastatic melanoma $(5,6)$, the success is not at present easily transferable to other cancers due to difficulties in collecting tumor-specific $\mathrm{T}$ cells (7-9). Transfusing virus-specific $\mathrm{T}$ cells is a standard modality for malignancies or infections related to viruses (10-12). TCR therapy functions by enabling cells with new receptors and the ability to recognize antigens against specific cancers and/or trigger other 


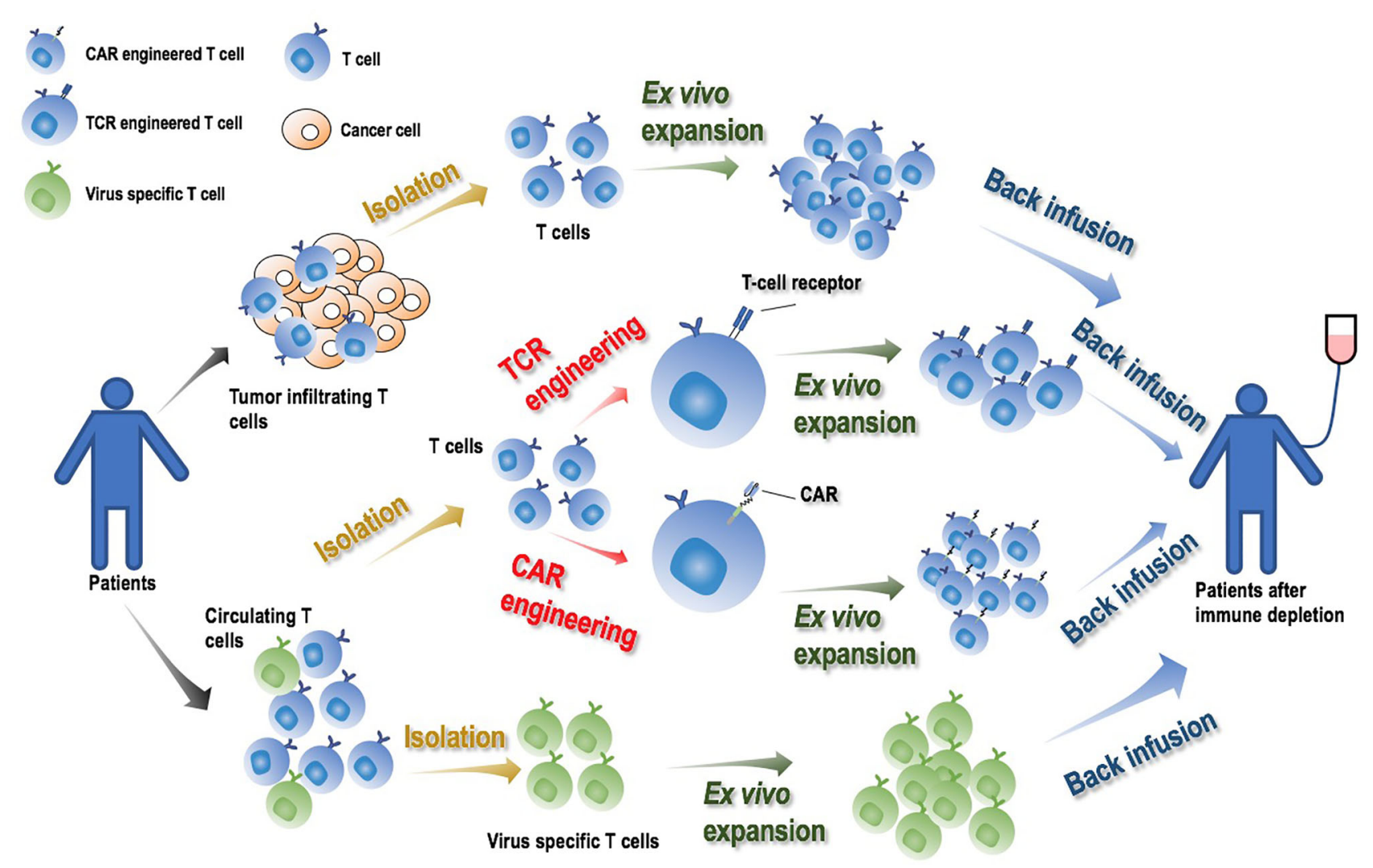

FIGURE 1 | Illustrative diagram on adoptive cell therapy (ACT) and its manufacturing process. By transfusing back one's own genetically engineered T cells or cancer-cognate lymphocytes that identify and attack cancer cells or foreign invasions, ACT activates the immune system and achieves its onco-therapeutic role. Engineered T cells expressing TCRs or CARs, TILs and virus specific T cells expanded ex vivo, are typically used to produce ACT. The manufacturing process is comprised of four major steps: 'T cell isolation', 'T cell engineering' (for TCR or CAR only), 'T cell ex vivo expansion', 'T cell back infusion'. Adjuvant chemo- or radiotherapies are conventionally applied to deplete patients' endogenous immune cells prior to ACT infusion to allow infused T cells to flourish.

cells to marsh attack on neoplastic cells (13). TCRs can be cloned from the reactive $\mathrm{T}$ cells infiltrating patient tumors (14) or humanized mouse models $(15,16)$, or through phage display (17). TCR must match the human leukocyte antigen (HLA) immune type of the patient genetically before achieving any functionality. To date, TCR therapies have demonstrated their efficacies in shrinking several types of tumors such as melanoma, synovial sarcoma, and colorectal cancers (18-20).

Transducing CAR-T cells to confer specificities on a targeted epitope such as CD19 and BCMA has demonstrated its oncotherapeutic efficacy. CARs are recombinant antigen receptors capable of grafting the specificity of a tumor antigen onto $\mathrm{T}$ cells via a single chain variable fragment ( $\mathrm{scFv}$ ) derived from an antibody. The aim is to redirect the specificity and function of immune cells and rapidly generate tumortargeting T cells. A CAR is comprised of four domains, i.e., an ectodomain that is responsible for tumor antigen recognition, an endodomain that contains one or several stimulatory molecules helping $\mathrm{T}$ cells persist, a hinge domain, and a transmembrane domain (21) (Figure 2). Once expressed on T cell surface, CAR acts as a switch that sets $\mathrm{T}$ cells to the attack mode when encountering a matching antigen (22). Any cell surface molecule can be, in principle, targeted by the CAR-T approach, filling in the antigen recognition gaps in the physiological $\mathrm{T}$ cell repertoire. Further, CARs do not require antigen processing and presentation and are more broadly applicable to HLA-diverse clinical cohorts. This brilliant idea of transforming T cells into a "living" drug gave birth to the CAR $\mathrm{T}$-cells, whose clinical activity was confirmed in various types of diseases including diffuse large B-cell lymphomas (23). CAR-T cells targeting CD19 have been reported to result in tumor remission of advanced chronic lymphocytic leukemia (CLL) and ALL patients who have failed multiple rounds of chemotherapy $(24,25)$.

CAR-T therapies have remained as boutique treatments available to a small number of patients despite our complete acknowledgement on their primary roles in rewiring the immune response against tumors. This paper identifies challenges faced by CAR-T therapies limiting their wide applications, reviews ongoing efforts circumventing such problems, and highlights opportunities brought by such promising technologies to academia and clinics (Table $\mathbf{1}$ ). 


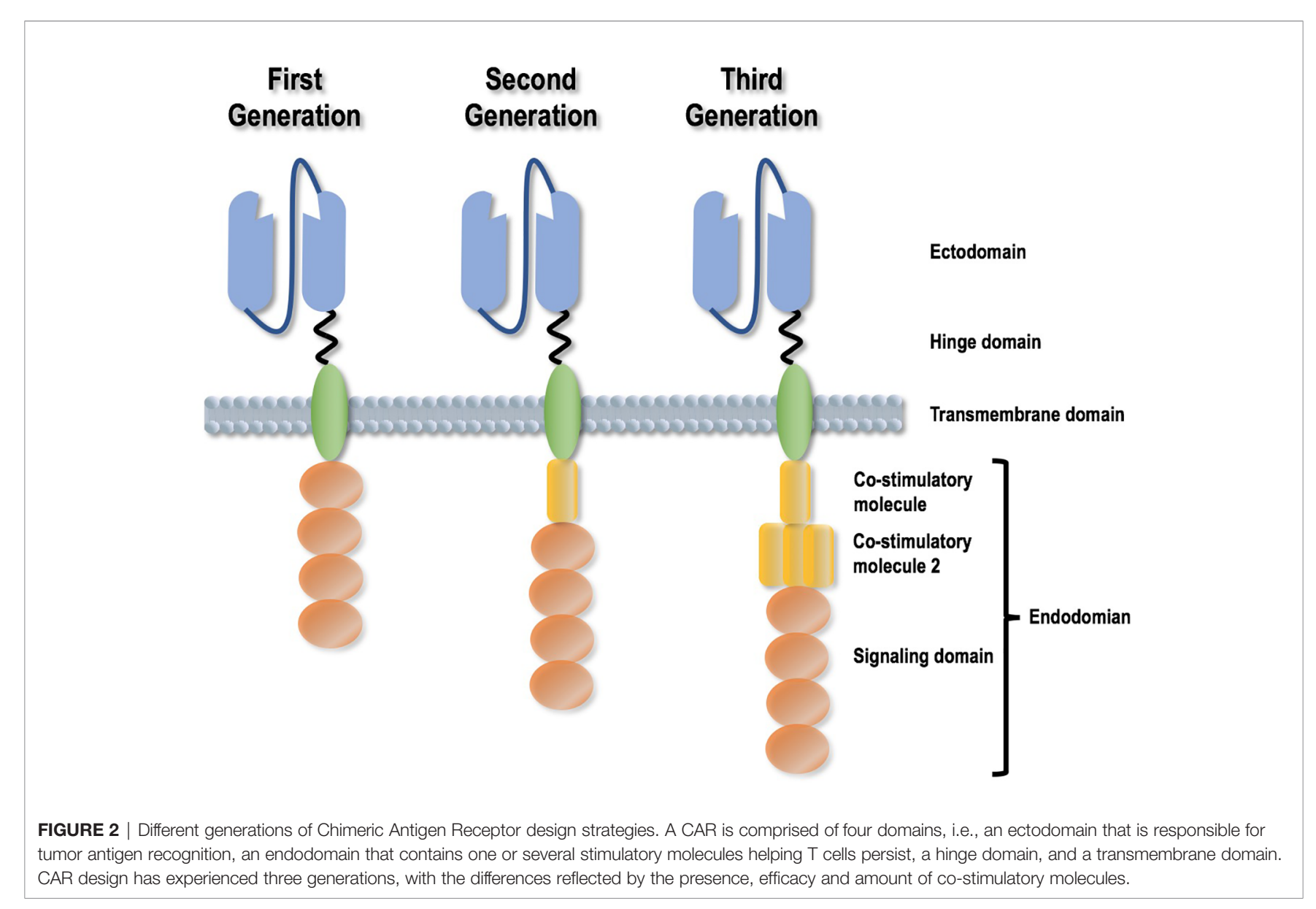

\section{PROBLEMS CHALLENGING CAR-T THERAPIES AND POSSIBLE SOLUTIONS}

\subsection{Off-Tumor Effect}

One limitation of CAR-T therapy is the requirement of the targets to be solely present on the surface of malignant cells but absent from that of normal cells. The cancer cell antigen epitope needs to be unique for $\mathrm{T}$ cell recognition without creating conditions associated with autoimmunity. However, many antigen epitopes found in cancers also have baseline expression levels in normal tissues (48), and targeting an antigen epitope with low specificity may result in severe consequences, namely the 'on-target off-tumor' effect, such as EGFR, HER2 $(49,50)$. For example, a severe transient inflammatory colitis was induced in all three patients (carrying refractory metastatic colorectal tumors) administered with autologous $\mathrm{T}$ lymphocytes expressing a murine TCR against human carcinoembryonic antigen (CEA) as CEA is also present in colonic mucosa (51). Off-tumor effects can also be mediated by another protein sharing similar binding affinity with TCR or antigen escape,

TABLE 1 | Challenges faced by the CAR-T therapies and the ongoing efforts.

\begin{tabular}{ll} 
Challenges & \multicolumn{1}{c}{ Ongoing efforts } \\
\hline Off-tumor effect & $\begin{array}{l}\text { Double tumor-associated antigen targeting, systematic safety testing of the targeted } \\
\text { therapies } \\
\text { Introduction of chemokine receptors to CAR-T cells, CAR-T cocktail immunotherapy, } \\
\gamma \delta T \text { cells } \\
\text { Inefficiency in solid tumor treatment }\end{array}$ \\
$\begin{array}{ll}\text { Optimization of ACT combination on a case-by-case basis } \\
\text { molecules }\end{array}$ \\
$\begin{array}{l}\text { Cytokine storm, tumor lysis syndrome } \\
\text { Myelosuppression, severe hepatotoxicity }\end{array}$ & $\begin{array}{l}\text { Modulation of co-stimulatory domains, suicide gene design } \\
\text { Pathological state of each patient }\end{array}$ \\
Difficulties in product generalization without & Using off-the-shelf third-party donor gene modified T cells
\end{tabular}

sacrificing product efficacy 
called the 'off-target off-tumor' effect. For example, MAGE-A3 is a cancer-testis antigen expressed in a wide array of malignancies including melanoma (52), cancers of ovary (53), lung (54), bladder (55), colon (56), breast (57), and has been proposed as an immunogenic target in clinics. However, targeting this antigen has resulted in many negative clinical results $(52,58)$, and even severe consequences (29). The first clinical example of the 'off-target off-tumor' effect mediated by TCR targeting MAGE-A3 is Titin (29), which is not related to MAGE-A3 neither structurally nor functionally. In this study, TCR targeting MAGE-A3 caused the death of two patients from heart failure due to the off-target binding to Titin on heart cells (29). In another study, two out of nine cancer patients died after receiving therapies targeting MAGE-A3 in a clinical trial of TCR-engineered T cells; it was found, on further examination, that a family member MAGE-A12 (also possibly, MAGE-A1, MAGE-A8, MAGE-A9) has a low level expression in brain tissue (30). Most top-ranked antigens that could be targeted by CAR-T are also expressed in potentially important normal tissues, such as HER2, EGFR, MUC1, PSMA, and GD2 (10). Although these examples are from failed clinical trials on TCR therapies, they are transferrable to CAR-T therapies and important lessons warranting special care on CAR design. Antigen escape may also result in failure in stimulating immune response. For instance, up to $30 \%$ of B-ALL (B cell acute lymphoblastic leukemia) patients receiving CART19 (anti-CD19 CAR-T cells) or blinatumomab (anti-CD19/CD3 antibodies) relapsed due to the loss of CD19 epitope in some tumor cells, imposing a major concern that challenges the efficacy of immunotherapies targeting CD19 (51, 59). Since approval in 2018, tisagenlecleucel (Kymriah, Novartis; Basel, Switzerland) and axicabtagene ciloleucel (Yescarta, Kite Pharma [Gilead]; Santa Monica, USA) are subjected to additional monitoring (CAR Tcell product performance in hematological malignancies before and after marketing authorization). However, the intact immune system in the mice used makes it a less accurate model of human disease than that using immunodeficient mice and thus could not be used to test the safety issues such as the ontarget offtumor activity and cytokinerelease syndrome (60).

To avoid or minimize the off-tumor effect, intensive research exploring target candidates with sufficient tumor-specificity and developing novel strategies for therapeutic design have gained traction. The Adaptimmune company has launched extensive safety examination to avoid undesirable therapeutic outcome. The 'double tumor-associated antigen targeting' strategy (i.e., targeting two instead of one tumor-associated antigen) has demonstrated its power in generating durable tumor remission; for instance, concomitant expression of CARs targeting CD19/ CD20 (28), CD19/CD22 (26), or CD19/CD123 (27) on T cells creates better therapeutic response than pooling $\mathrm{T}$ cells carrying either CAR together. However, targeting two tumor-associated antigens may need to reduce the dose of CARs targeting each antigen as the total amount of CAR-T cells could not be increased without limit for the sake of safety; thus, how to appropriately balance the proportion of each CAR expressed on the modulated $\mathrm{T}$ cells is of vital importance to create the desired therapeutic efficacy where rigorous computational simulations and experimental validations are needed. It was also suggested that CAR-T cells targeting CD19 induced B precursor acute lymphoblastic leukemia lineage switch towards a more plastic state (61), suggesting the potential of combining therapies targeting cancer stem cells with CART19 or blinatumomab in restoring the sensitivity of cancer cells to anti-CD19 drugs. Despite these experimental efforts, computational approaches, such as establishing databases for target scan and simulating the efficacy of CARs $(62,63)$, may considerably accelerate this process.

\subsection{Inefficiency}

\subsubsection{Inefficiency in Solid Tumor Treatment}

The field of CAR-T therapies awaits a clear demonstration of their clinical efficacies in solid tumor treatment, which ultimately determines the validity of this novel modality in the battle against cancer. Though designed to be capable of selectively targeting specific cancer cells, CAR-T cells need to be able to reach the tumor site to take on any effect. While trafficking is not a problem for blood cancers as evidenced by numerous clinical successes (64-67), it is likely to be a bottleneck for delivering therapeutic cells to solid tumors due to the strong immunosuppressive tumor microenvironment. Introducing chemokine receptors such as IL13R $\alpha 2$ (68), CCR4 (69) and CCR242 to CAR-T cells has been indicated to improve these immune cell trafficking in vivo and infiltration into tumors. A recent study reported the feasibility of using CAR-T cocktail immunotherapy, i.e., combined use of CAR-T cells against EGFR and $\mathrm{CD} 133$, in the treatment of cholangiocarcinoma, where patients receiving such a therapeutic modality achieved an 8.5and 4.5-month partial response, respectively (33). Also in 2017, a phase I clinical trial involving 23 metastatic colorectal cancer patients was launched to test the efficacy and safety of a CAR-T product targeting TAG-72 convolving a CD3 $\zeta$ intracellular signaling domain, and the results showed effective CAR-T cell trafficking to the tumor site and reduced TAG-72 expression without clear evidence of off-tumor toxicity, despite symptoms of anti-CAR immune response in some patients (34). Specific type of immune cells such as $\gamma \delta$ T cells have been proposed promising for use in cellular therapy targeting solid tumors $(70,71)$. Another strategy is to augment the anti-tumor function of CAR-T cells by concomitantly targeting tumor antigens and tumor associated fibroblasts. It is shown that CAR-T cells targeting fibroblast activation protein $\alpha$ together with tumorassociated antigens could considerably enhance the anti-tumor efficacies of CAR-T cells targeting either part alone (36). Also possible is to combine CAR-T therapies with the immune checkpoint inhibitors such as anti-PD-1, anti-CTLA4, OX40, and their combinations such as the joint use of anti-PD-1 and agonist OX40 to create a favorable microenvironment for CAR-T therapies to take on the effect $(31,72,73)$. Mechanisms of aforementioned strategies need to be completely understood before any other novel strategies can be brought up including, e.g., how T cells are activated by CARs and how each component 
of CARs is optimized to enable efficient targeting and killing of CAR-T cells against solid tumors.

Extensive computational efforts have been devoted to explore molecular features of T cells, B cells, NK cells or any of their combinations, in tumors or tumor microenvironment for the prognosis of the immunotherapeutic response of a solid tumor $(35,74,75)$, which not only helps clinicians make correct decision on whether an immunotherapy or which therapeutic modality is feasible to give, but also contributes in identifying the molecular driving force leading to immunotherapeutic resistance towards improved drugging strategies.

\subsubsection{Differential Efficacies of Co-Stimulatory Molecules}

The patients' endogenous immunity needs to be suppressed preCAR-T treatment to allow the persistence and expansion of infused T cells (76). Patients thus suffer from the adverse effects of adjunctive treatments such as chemo- and/or radio- therapies, rendering the outcome of the standard modality double-edged, i.e., improved efficacy is in sacrifice of patients' immunity. The addition of co-stimulatory domains may take over the role of adjunctive therapies by empowering CAR-T cells to proliferate and expand. Differential use of co-stimulatory molecules is needed for different types of cancers. For example, coupling $\mathrm{CD} 20$ with $\mathrm{CD} 137$ and $\mathrm{CD} 3 \zeta$ can cause prolonged tumor regression for advanced diffuse large B cell lymphomas (39); autologous or donor-derived $\mathrm{T}$ cells expressing a CAR that targets CD19 and harbors CD137 and the CD3 $\zeta$ moiety can cause regression of extramedullary $\mathrm{B}$-cell lineage acute lymphocytic leukemia (37). It was demonstrated that CD137 is a more effective costimulatory domain of CD19 CAR-T cells than CD28 regarding therapeutic persistency in clinical trials (38). Thus, balancing components of the immune system to reach the desired clinical outcome, as featured by CAR-T therapies, represents a new way of conceptualizing dosing in medicine and needs to be optimized, on a case-by-case basis, towards each type of malignancy or even per patient to achieve the best response.

\subsection{Over-Inefficiency}

\subsubsection{Cytokine Storm and Tumor Lysis Syndrome}

CAR-T is advantageous in the relatively short response time it takes to show effects (often in days to weeks). However, it is dangerous to trigger such a dramatic immunogenic response that implies elevated potential for the occurrence of uncontrollable or even lethal side effects. For instance, the British company TeGenero almost killed six volunteers in a phase I study testing the efficacy of TGN1412 (an anti-CD28 monoclonal antibody) in the treatment of B-cell tumors and autoimmune disorders due to the induction of toxic levels of cytokines in vivo, referred to as the cytokine storm (77). The CAR-T associated cytokine storm can occur within the first few days after $\mathrm{T}$ cell infusion characterized by high serum cytokine levels, fever, vascular leakage, hypotension and even death (78). Norelli et al. simulated CAR-T associated cytokine storm using humanized mice, in which the endogenous immune system was replaced with human immune cells, thereby avoiding the induction of graft-versus-host disease after human CAR T cell infusion (41). Such an immune avalanche can also lead to the tumor lysis syndrome, which occurs when many tumor cells die rapidly following the release of cell contents into the blood and is caused by the infiltration of a large amount of lysed components of dead tumor cells into the blood. The safety issues linked to CAR-T have now drawn considerable attention. Several strategies have been proposed to control the side effects and launched with preclinical success. For example, suicide genes can be designed to easily ablate CAR-T cells and activated on abnormal CAR-T cell persistence or under acute toxicity, and such a technology is called 'suicide gene design' (79). Inducible Caspase 9, namely iCasp9, is a well-studied suicide gene for CAR-T therapies $(40,80)$. It consists of iCasp9 (the intracellular domain of the human Caspase 9 protein) that functions in inducing cell apoptosis and a human FK506 binding protein that dimerizes on the presence of small molecules such as AP1903 (81). Activation of iCasp9 in patients transplanted with CAR-T cells could rapidly induce the $\mathrm{T}$ cell apoptosis to cease the cytokine storm (82). Effective elimination of T cells has been observed in the pre-clinical studies on CAR-T cells carrying the iCasp9 design (83); joint use of iCasp9 and anti-GD2 CAR-T cells have been administrated in clinics, with one being completed in US (NCT02107963) and the other under recruitment in China (NCT02992210). Aside from these clinical successes, novel design on suicide genes and endeavors on other strategies as well as standardized clinical practice in validating the efficacy of CAR-T therapies await to be established.

\subsubsection{Myelosuppression and Severe Hepatotoxicity}

The CAR-T cells can persist for years with the potential of preventing cancer relapse. This, however, may lead to serious safety concerns including myelosuppression and severe hepatotoxicity (44). Han W. D. et al. reported in 2015 their observation of a remarkable decrease followed by a gradual augmentation of blasts in the bone marrow after administrating autologous CART-33 cells to an acute myeloid leukemia (AML) patient (45). These warrant further efforts to personalize the effective drug duration of CAR-T products according to, e.g., the genetic profile and pathological state of each patient.

\subsection{Difficulties in Product Generalization Without Sacrificing Product Efficacy}

Product comparability imposes a great concern towards the largescale application of CAR-T therapies. It is challenging to clearly define the dosage, design and calculation method of infused CAR-T cells that considerably affect the efficacy of CAR-T therapies. The total number of CAR-T cells infused varies from 108 to 1010, in clinical practice, according to the body surface area and weight of the patient. It is also possible to determine the amount of infused CAR-T cells by the CAR-positive cohort. How to reach consensus on the requirements of these detailed specifications to standardize the use of CAR-T while taking into account the heterogeneous nature of CAR-T therapy remains challenging. Some groups have been exploring the feasibility of using third party donor gene 
modified T cells for treating viral infections $(46,47)$, with the hope of creating a universal cell therapy. For CAR-T therapy, fully compatible cell bank, low immunogenic umbilical cord blood cells, allogeneic natural killer cells, and gene-editing $\mathrm{T}$ cells have been considered as the off-the-shelf sources for the sake of uniformity and safety $(84,85)$.

\section{WHEN ONCO-IMMUNOTHERAPY MEETS COLD ATMOSPHERIC PLASMA}

\subsection{Cold Atmospheric Plasma}

Cold atmospheric plasma (CAP) is an emerging oncotherapeutic tool (32). It generates a collection of reactive oxygen and nitrogen species (RONS) such as hydrogen peroxide $\left(\mathrm{H}_{2} \mathrm{O}_{2}\right)$, ozone $\left(\mathrm{O}_{3}\right)$, singlet oxygen $(\mathrm{O})$, hydroxyl radical $(\mathrm{OH} \cdot)$, superoxide $\left(\mathrm{O}^{2-}\right)$, nitric oxide $(\mathrm{NO} \cdot)$, anionic $\left(\mathrm{OONO}^{-}\right)$and protonated $(\mathrm{ONOOH})$ forms of peroxynitrite. The cocktail of CAP is comprised of long-lived species such as $\mathrm{H}_{2} \mathrm{O}_{2}$ and short-lived species such as $\mathrm{O}$. While long-lived species function inside cells to induce apoptosis or necrosis via imposing oxidative/nitrosative stress to cells, short-lived species could induce immunogenic cell death that kill cancer cells located at the long distance (86). Both long- and short-lived species function together to trigger selective death of cancer cells. The selectivity of CAP on cancer cells is achieved via interactions between various components and malignant cells. Malignant cells typically have a high local concentration of catalysis on the surface that prevent $\mathrm{H}_{2} \mathrm{O}_{2}$ entry; $\mathrm{H}_{2} \mathrm{O}_{2}$ and peroxynitrite interact to generate $\mathrm{O}$ and amplify its signaling that ultimately leads to $\mathrm{H}_{2} \mathrm{O}_{2}$ influx; $\mathrm{H}_{2} \mathrm{O}_{2}$, once entering cells, modulate intracellular redox level to halt cells at a certain cell cycle stage, trigger apoptosis or necrosis depending on the intracellular redox level after CAP exposure (87).

The selectivity of CAP against cancer cells has been demonstrated in several types of malignancies including e.g. melanoma (88), pancreatic cancer (89), and breast cancer (90). In clinics, the first clinical trial testing the efficacy of CAP in being used as an oncotherapy has been issued in July 2019. Though many studies have reported the use of CAP in rewiring the resistance of cancer cells towards chemotherapies $(91,92)$, synergies between CAP and drugs such as chemotherapy or immunotherapy have not been tested or launched in clinics. Below, we forecast and discuss the potential aid of CAP in enhancing the efficacy of immunotherapies and preventing its possible side effects.

\subsection{CAP May Enhance CAR Efficiency by Boosting Cancer Cells' Sensitivity to Immunotherapies}

The multimodality nature of CAP could selectively kill cancer cells by breaking their more vulnerable redox equilibrium as compared with normal cells (90), induce immunogenic cell death (ICD) by increasing the visibility of malignant cells to immune cells $(86,93)$, and edit tumor microenvironment (TME) towards a more immune-sensitive environment by switching M2 macrophages (immunosuppressive) to the M1 state (proinflammatory) $(94,95)$, suggesting its potential in creating synergies with CAR-T cells in treating solid tumors. During cancer immunotherapy, cancer cells release antigens that are presented by antigen-presenting cells (APCs) followed by activation of $\mathrm{T}$ cells that infiltrate tumors and kill cancer cells (96). ICD, inducible by oxidative stress and capable of triggering the adaptive immune response, can transform non-immunogenic cells to immunogenic cells towards enhanced antigenic substance release that promotes anti-tumor immunity (96). Accumulating in vitro and in vivo evidences have demonstrated the efficacy of CAP in inducing ICD in many cancers such as colorectal tumors, pancreatic cancers, glioblastoma, and melanoma (93, 97-101), suggestive of the role of CAP in sensitizing tumors to immunotherapies (Figure 3). In addition, we found previously that CAP could selectively kill triple negative breast cancer cells, and this type of breast cancers is featured by high cancer stemness (90), implicating the functionality of CAP in targeting cancer stem cells; and such a property can be used to rewire lineage switch caused by CAR-T cells against CD19 for prolonged therapeutic efficacy and reduced recurrence rate. Importantly, CAP could be administrated in the form of liquids (102), thus the reactive species it delivers could more easily infiltrate solid tumors than engineered $\mathrm{T}$ cells due to their much smaller size, boosting CAP's role in assisting CAR-T therapies for improved efficacy delivery.

\subsection{CAP May Avoid Immune Over-Reaction by Reducing the Dose of Immunotherapies}

The aforementioned side effects caused by uncontrolled overefficiency of CAR-T cells (either via fast response or long-lasting effect) may be tempered by taking the joint use of CAP and immunotherapies by creating synergies. ROS-inducing therapies have been shown capable of stimulating the immune system and sensitizing resistant cancers to chemo- and immunotherapies $(103,104)$. Mechanistically, ROS could facilitate the release of damage-associated molecular patterns (DAMPs) into TME that lead to activated macrophages and enhanced antigen presentation, and promote the expression of major histocompatibility complex (MHC) I (105) that counteracts the intratumoral downregulation of $\mathrm{CD} 8+\mathrm{T}$ cell response towards improved tumor antigen presentation in TME (Figure 3). Thus, CAP, relying on ROS to take on actions, may reduce the amount and frequency of CAR-T cells infused to the patient to achieve the desired therapeutic efficacy, and thus reduce the probability of causing side effects related to over-activated immune response. On the other hand, CAP is a mild approach with multiple clinical applications, the safety of which has been rigorously examined and clinically validated for years (106-111). Being a treatment strategy with multi-modality nature, CAP has demonstrated its power in creating synergies with chemotherapies such as Temozolomide (91) and Bortezomib (92), as well as rewiring drug resistant cells to a chemo-sensitive state (112). It is thus worthwhile to investigate the potential synergies created between CAP and CAR-T therapies for improved efficacy and reduced side effects. 


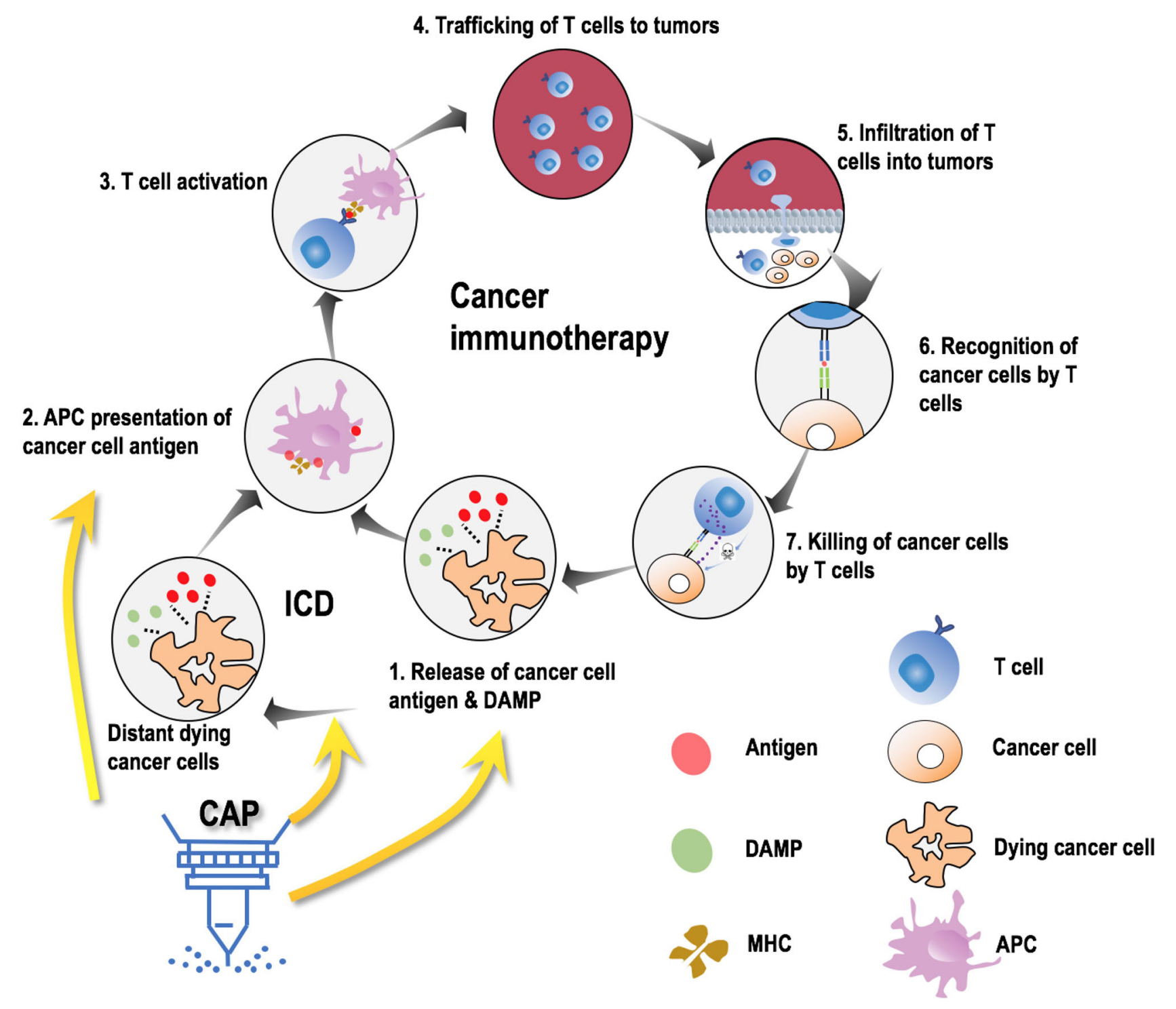

FIGURE 3 | Possible molecular mechanisms leading to synergies between CAP and onco-immunotherapies. Cancer immunotherapy is comprised of 7 steps, i.e., release of cancer cell antigens and damage associated molecular patterns (DAMPs), antigen presentation cell (APC) presentation of cancer cell antigens through major histocompatibility molecules (MHC), T cell activation, trafficking of T cells to the site of tumors, infiltration of T cells to tumors, recognition of cancer cells by $\mathrm{T}$ cells, and killing of cancer cells by T cells. Cold atmospheric plasma (CAP) avails in this process by primarily contributing to the first two steps in three aspects, i.e. promoting immunogenic cell death (ICD), promoting MHC expression, facilitating DAMP release.

\section{DISCUSSION}

ACT immunotherapies have demonstrated tremendous efficacies in the control of complex diseases such as cancer. Among them, CAR-T therapies have considerably enriched the current oncotherapeutic modalities and revolutionized our conception in treatment and dosing given their extreme heterogeneity and flexibility by design. This, on one hand, provides us with opportunities for curing highly variable complex diseases and taking personalized medicine to an extreme and, on the other hand, imposes us tremendous challenges regarding appropriate harness on such therapeutic strategies and their large-scale production as well as applications.

The promise delivered by CAR-T therapies is tempered by the safety concerns, which primarily include 'off-tumor' toxicity, cytokine storm and tumor lysis syndrome, myelosuppression and severe hepatotoxicity. Besides concerns relevant to CAR design, safety issues may also arise from inappropriate manufacturing. For instance, due to an unintentional introduction of the CAR gene into one single leukemic B cell during $\mathrm{T}$ cell manufacturing, the mistakenly engineered product bound in cis to the CD19 epitope of leukemic cells and masked 
them from being recognized by anti-CD19 CAR, leading to patient relapse and CTL019 resistance (113). Thus, despite the ongoing efforts paid to improve our control on CAR-T therapies, special care needs to be paid to the manufacturing process and quality of CAR-T cells. These, collectively, require the establishment of novel strategies and technologies through joint efforts from biologists, computational scientists, clinicians and technicians.

How to deliver the desirable efficacy constitutes another major concern limiting the wide applications of CAR-T therapies. These mainly include inefficiency in treating solid tumors, differential efficacies of co-stimulatory molecules, and difficulties in product generalization without sacrificing or compromising product efficacy. Despite the ongoing effort and conventional approaches in solving these issues, we need to keep aware of emerging oncotherapeutic tools and their potential in enhancing the efficacies of CAR-T therapies. For example, CAP, whose selectivity against cancer cells and multi-modality nature may enable it an ideal adjuvant therapy or jointly used approach for CAR-T therapies to sensitize resistant solid tumors to immunotherapies and reduce the amount of infused CAR-T cells to both achieve the desired efficacy and solve the safety problem (Figure 4). Yet, how to jointly administrating CAP and CAR-T to patients such as the interval and frequency need to be carefully tested and designed to enable desirable outcome. It is also possible that $\mathrm{T}$ cells behave differently on CAP exposure that could be taken advantages of which, however, requires intensive investigations before any conclusion could be drawn.

CAR-T therapies could be used to reprogram $\mathrm{T}$ cells towards targeting tumor-specific antigens given a patient, taking oncotherapeutics to an extreme of personalization. This, however, may demand systematic genetic screen for each patient on mutations unique to tumors and impose too much challenges on its design, cost and production, largely restricting its wide application. How to find a proper balance between the personalization and generalization of such therapies to get each patient benefit from this promising revolutionary life-saving and emerging first-line therapeutic approach remains challenging.

\section{CONCLUSION}

In conclusion, it is crucial to find a balance between personalization and generalization towards improved controllability on the specificity and efficacy of CAR-T therapies. To be specific, CAR should be designed with care to avoid the off-tumor effect, enhance solid tumor treatment efficacy, improve product comparability, and resolve issues such as differential efficacies of costimulatory molecules, cytokine storm, tumor lysis syndrome, myelosuppression and severe hepatotoxicity. Importantly, we propose the potential synergies between immunotherapies and $\mathrm{CAP}$, an emerging onco-therapeutic approach exploiting unique

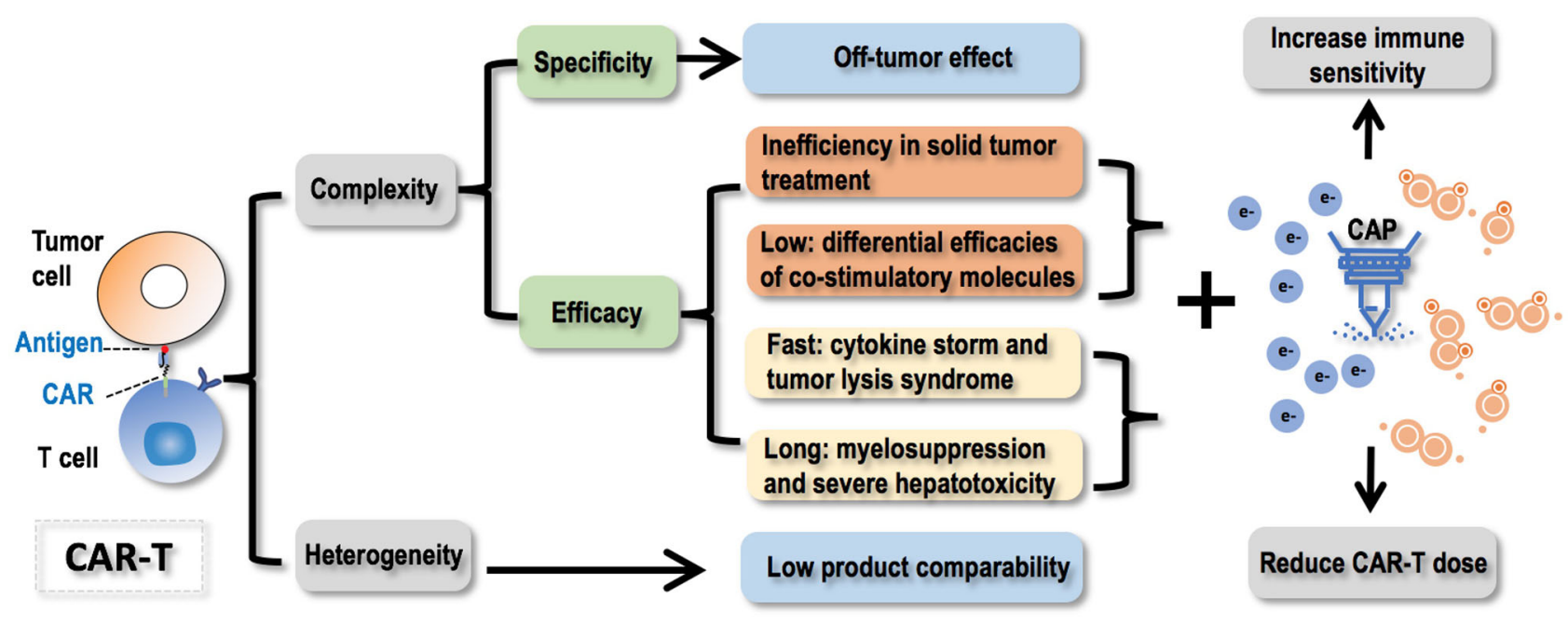

FIGURE 4 | Conceptual scheme illustrating challenges faced by CAR-T therapies, opportunities CAP provided to resolve these problems, and the ultimate goal towards the complete harness of CAR-T cells as a key element of the next generation of precision medicine. CAR-T therapies are difficult to control and heterogeneous in nature. Regarding the 'uncontrollability', failure in controlling the specificity will lead to the off-tumor effect; failure in controlling the efficacy can be casted from 4 aspects that fall into two categories, i.e., 'inefficiency' including 'inefficiency in solid tumor treatment' and 'differential efficacies of co-stimulatory molecules', 'over-efficiency' including 'cytokine storm and tumor lysis syndrome due to too fast therapeutic response' and 'myelosuppression and severe hepatotoxicity' due to long-lasting treatment efficacy. Regarding the 'heterogeneity' feature, it will lead to low product comparability. CAP (cold atmospheric plasma) offers opportunities solving these challenges by increasing the immune sensitivity of cancer cells and reducing the dose of CAR-T to achieve improved or comparable efficacy with reduced recurrence and increased safety. Faced by these problems, joint efforts from biologists, computational scientists, and clinicians are needed to collaboratively advance the strategies and technologies to improve our controllability on the specificity and efficacy of CAR-T therapies, as well as find a balance between the personalization and generalization of such promising approaches. 
chemical and physical features of the fourth state of matter to deliver mild yet effective doses of reactive species, towards improved immunotherapeutic efficacies against cancers with reduced side effects.

\section{AUTHOR CONTRIBUTIONS}

$\mathrm{XD}$ conceived the study and drafted the manuscript. XD, YC and JL prepared the figures and tables. XD provided the financial support. All authors have read and proved the content of the manuscript.

\section{REFERENCES}

1. Cohen JE, Merims S, Frank S, Engelstein R, Peretz T, Lotem M. Adoptive Cell Therapy: Past, Present and Future. Immunotherapy (2017) 9(2):183-96. doi: 10.2217/imt-2016-0112

2. Choi D, Kim TG, Sung YC. The Past, Present, and Future of Adoptive T Cell Therapy. Immune Network (2012) 12(4):139-47. doi: 10.4110/ in.2012.12.4.139

3. Jiang L, Wang W. Genetically Modified Immune Cells for Cancer Immunotherapy. Sci China Life Sci (2018) 61(10):1277-9. doi: 10.1007/ s11427-018-9395-0

4. Veiga-Parga T, Sehrawat S, Rouse BT. Role of Regulatory T Cells During Virus Infection. Immunol Rev (2013) 255(1):182-96. doi: 10.1111/imr.12085

5. Nguyen LT, Saibil SD, Sotov V, Le MX, Khoja L, Ghazarian D, et al. Phase II Clinical Trial of Adoptive Cell Therapy for Patients With Metastatic Melanoma With Autologous Tumor-Infiltrating Lymphocytes and LowDose Interleukin-2. Cancer Immunol Immunother: CII (2019) 68(5):773-85. doi: 10.1007/s00262-019-02307-x

6. Prickett TD, Crystal JS, Cohen CJ, Pasetto A, Parkhurst MR, Gartner JJ, et al. Durable Complete Response From Metastatic Melanoma After Transfer of Autologous T Cells Recognizing 10 Mutated Tumor Antigens. Cancer Immunol Res (2016) 4(8):669-78. doi: 10.1158/2326-6066.CIR-15-0215

7. Dudley ME, Yang JC, Sherry R, Hughes MS, Royal R, Kammula U, et al. Adoptive Cell Therapy for Patients With Metastatic Melanoma: Evaluation of Intensive Myeloablative Chemoradiation Preparative Regimens. J Clin Oncol (2008) 26(32):5233-9. doi: 10.1200/JCO.2008.16.5449

8. Yee C. Adoptive T-Cell Therapy for Cancer: Boutique Therapy or Treatment Modality? Clin Cancer Res: An Off J Am Assoc Cancer Res (2013) 19(17):4550-2. doi: 10.1158/1078-0432.CCR-13-1367

9. Lee N, Zakka LR, Mihm MC Jr, Schatton T. Tumour-Infiltrating Lymphocytes in Melanoma Prognosis and Cancer Immunotherapy. Pathology (2016) 48(2):177-87. doi: 10.1016/j.pathol.2015.12.006

10. Wada S, Suzuki T, Kitazume K, Fujita A, Shimizu S. Systemic Epstein-Barr Virus-Positive T-Cell Lymphoproliferative Disorders of Childhood With Fulminant Leukocytosis and Tumor Lysis: A Case Report With Autopsy Findings. Int J Hematol (2017) 108:112-7. doi: 10.1007/s12185-017-2380-4

11. Proff J, Walterskirchen C, Brey C, Geyeregger R, Full F, Ensser A, et al. Cytomegalovirus-Infected Cells Resist T Cell Mediated Killing in an HLARecognition Independent Manner. Front Microbiol (2016) 7:844. doi: $10.3389 /$ fmicb.2016.00844

12. Rosewell Shaw A, Porter CE, Watanabe N, Tanoue K, Sikora A, Gottschalk S, et al. Adenovirotherapy Delivering Cytokine and Checkpoint Inhibitor Augments CAR T Cells Against Metastatic Head and Neck Cancer. Mol Ther: J Am Soc Gene Ther (2017) 25(11):2440-51. doi: 10.1016/ j.ymthe.2017.09.010

13. Haji-Fatahaliha M, Hosseini M, Akbarian A, Sadreddini S, Jadidi-Niaragh F, Yousefi M. CAR-Modified T-Cell Therapy for Cancer: An Updated Review. Artif Cells Nanomed Biotechnol (2016) 44(6):1339-49. doi: 10.3109/ 21691401.2015.1052465

14. Johnson LA, Heemskerk B, Powell DJ Jr, Cohen CJ, Morgan RA, Dudley ME, et al. Gene Transfer of Tumor-Reactive TCR Confers Both High Avidity and

\section{FUNDING}

This work was supported by the National Natural Science Foundation of China (Grant No. 81972789, 82004397), Fundamental Research Funds for the Central Universities (Grant No. JUSRP22011), Technology Development Funding of Wuxi (Grant No. WX18IVJN017), Major Project of Science and Technology in Henan Province (Grant No. 192102310437), the Major Project of TCM research in Henan Province (Grant No. 2019ZYZD02, 2018ZYZD01). The funding bodies played no role in the design of the study and collection, analysis, and interpretation of data and in writing the manuscript.

Tumor Reactivity to Nonreactive Peripheral Blood Mononuclear Cells and Tumor-Infiltrating Lymphocytes. J Immunol (2006) 177(9):6548-59. doi: 10.4049/jimmunol.177.9.6548

15. Parkhurst MR, Joo J, Riley JP, Yu Z, Li Y, Robbins PF, et al. Characterization of Genetically Modified T-Cell Receptors That Recognize the CEA:691-699 Peptide in the Context of HLA-A2.1 on Human Colorectal Cancer Cells. Clin Cancer Res: An Off J Am Assoc Cancer Res (2009) 15(1):169-80. doi: 10.1158/1078-0432.CCR-08-1638

16. Cohen CJ, Zheng Z, Bray R, Zhao Y, Sherman LA, Rosenberg SA, et al. Recognition of Fresh Human Tumor by Human Peripheral Blood Lymphocytes Transduced With a Bicistronic Retroviral Vector Encoding a Murine Anti-P53 TCR. J Immunol (2005) 175(9):5799-808. doi: 10.4049/ jimmunol.175.9.5799

17. Varela-Rohena A, Molloy PE, Dunn SM, Li Y, Suhoski MM, Carroll RG, et al. Control of HIV-1 Immune Escape by CD8 T Cells Expressing Enhanced T-Cell Receptor. Nat Med (2008) 14(12):1390-5. doi: 10.1038/ nm.1779

18. Inderberg EM, Walchli S, Myhre MR, Trachsel S, Almasbak H, Kvalheim G, et al. T Cell Therapy Targeting a Public Neoantigen in Microsatellite Instable Colon Cancer Reduces In Vivo Tumor Growth. Oncoimmunology (2017) 6 (4):e1302631. doi: 10.1080/2162402x.2017.1302631

19. Zhang C, Wang Z, Yang Z, Wang M, Li S, Li Y, et al. Phase I Escalating-Dose Trial of CAR-T Therapy Targeting CEA(+) Metastatic Colorectal Cancers. Mol Ther: J Am Soc Gene Ther (2017) 25(5):1248-58. doi: 10.1016/ j.ymthe.2017.03.010

20. Robbins PF, Morgan RA, Feldman SA, Yang JC, Sherry RM, Dudley ME, et al. Tumor Regression in Patients With Metastatic Synovial Cell Sarcoma and Melanoma Using Genetically Engineered Lymphocytes Reactive With NY-ESO-1. J Clin Oncol (2011) 29(7):917-24. doi: 10.1200/jco.2010.32.2537

21. Maus MV, Grupp SA, Porter DL, June CH. Antibody-Modified T Cells: CARs Take the Front Seat for Hematologic Malignancies. Blood (2014) 123 (17):2625-35. doi: 10.1182/blood-2013-11-492231

22. Labanieh L, Majzner RG, Mackall CL. Programming CAR-T Cells to Kill Cancer. Nat Biomed Eng (2018) 2(6):377-91. doi: 10.1038/s41551-018-0235-9

23. Barbet J, Foucquier A, Thomas Y. Therapeutic Progress in Oncology: Towards a Revolution in Cancer Therapy? (2020). Available at: https://books.google. com/books?id=OuDSDwAAQBAJ.

24. Kalos M, Levine BL, Porter DL, Katz S, Grupp SA, Bagg A, et al. T Cells With Chimeric Antigen Receptors Have Potent Antitumor Effects and can Establish Memory in Patients With Advanced Leukemia. Sci Transl Med (2011) 3(95):95ra73. doi: 10.1126/scitranslmed.3002842

25. Brentjens RJ, Davila ML, Riviere I, Park J, Wang X, Cowell LG, et al. CD19Targeted T Cells Rapidly Induce Molecular Remissions in Adults With Chemotherapy-Refractory Acute Lymphoblastic Leukemia. Sci Transl Med (2013) 5(177):177ra38. doi: 10.1126/scitranslmed.3005930

26. Jin A, Feng J, Wei G, Wu W, Yang L, Xu H, et al. CD19/CD22 Chimeric Antigen Receptor T-Cell Therapy for Refractory Acute B-Cell Lymphoblastic Leukemia With FLT3-ITD Mutations. Bone Marrow Transplant (2020) 55(4):717-21. doi: 10.1038/s41409-020-0807-7

27. Ruella M, Barrett DM, Kenderian SS, Shestova O, Hofmann TJ, Perazzelli J, et al. Dual CD19 and CD123 Targeting Prevents Antigen-Loss Relapses 
After CD19-Directed Immunotherapies. J Clin Invest (2016) 126(10):381426. doi: $10.1172 /$ JCI87366

28. Zah E, Lin MY, Silva-Benedict A, Jensen MC, Chen YY. T Cells Expressing CD19/CD20 Bispecific Chimeric Antigen Receptors Prevent Antigen Escape by Malignant B Cells. Cancer Immunol Res (2016) 4(6):498-508. doi: 10.1158/2326-6066.CIR-15-0231

29. Linette GP, Stadtmauer EA, Maus MV, Rapoport AP, Levine BL, Emery L, et al. Cardiovascular Toxicity and Titin Cross-Reactivity of AffinityEnhanced T Cells in Myeloma and Melanoma. Blood (2013) 122(6):86371. doi: 10.1182/blood-2013-03-490565

30. Morgan RA, Chinnasamy N, Abate-Daga D, Gros A, Robbins PF, Zheng Z, et al. Cancer Regression and Neurological Toxicity Following Anti-MAGEA3 TCR Gene Therapy. J Immunother (2013) 36(2):133-51. doi: 10.1097/ CJI.0b013e3182829903

31. Jahan N, Talat H, Alonso A, Saha D, Curry WT. Triple Combination Immunotherapy With GVAX, Anti-PD-1 Monoclonal Antibody, and Agonist Anti-OX40 Monoclonal Antibody is Highly Effective Against Murine Intracranial Glioma. Oncoimmunology (2019) 8(5):e1577108. doi: 10.1080/2162402X.2019.1577108

32. Dai X, Bazaka K, Richard DJ, Thompson ERW, Ostrikov KK. The Emerging Role of Gas Plasma in Oncotherapy. Trends Biotechnol (2018) 36(11):118398. doi: 10.1016/j.tibtech.2018.06.010

33. Feng KC, Guo YL, Liu Y, Dai HR, Wang Y, Lv HY, et al. Cocktail Treatment With EGFR-Specific and CD133-Specific Chimeric Antigen ReceptorModified T Cells in a Patient With Advanced Cholangiocarcinoma. J Hematol Oncol (2017) 10(1):4. doi: 10.1186/s13045-016-0378-7

34. Hege KM, Bergsland EK, Fisher GA, Nemunaitis JJ, Warren RS, McArthur JG, et al. Safety, Tumor Trafficking and Immunogenicity of Chimeric Antigen Receptor (CAR)-T Cells Specific for TAG-72 in Colorectal Cancer. J Immunother Cancer (2017) 5:22. doi: 10.1186/s40425-017-0222-9

35. Li B, Li TW, Pignon JC, Wang BB, Wang JZ, Shukla SA, et al. Landscape of Tumor-Infiltrating T Cell Repertoire of Human Cancers. Nat Genet (2016) 48(7):725-+. doi: 10.1038/ng.3581

36. Lo A, Wang LS, Scholler J, Monslow J, Avery D, Newick K, et al. TumorPromoting Desmoplasia Is Disrupted by Depleting FAP-Expressing Stromal Cells. Cancer Res (2015) 75(14):2800-10. doi: 10.1158/0008-5472.CAN-14-3041

37. Dai H, Zhang W, Li X, Han Q, Guo Y, Zhang Y, et al. Tolerance and Efficacy of Autologous or Donor-Derived T Cells Expressing CD19 Chimeric Antigen Receptors in Adult B-ALL With Extramedullary Leukemia. Oncoimmunology (2015) 4(11):e1027469. doi: 10.1080/2162402X.2015.1027469

38. Long AH, Haso WM, Shern JF, Wanhainen KM, Murgai M, Ingaramo M, et al. 4-1BB Costimulation Ameliorates T Cell Exhaustion Induced by Tonic Signaling of Chimeric Antigen Receptors. Nat Med (2015) 21(6):581-90. doi: $10.1038 / \mathrm{nm} .3838$

39. Wang Y, Zhang WY, Han QW, Liu Y, Dai HR, Guo YL, et al. Effective Response and Delayed Toxicities of Refractory Advanced Diffuse Large BCell Lymphoma Treated by CD20-Directed Chimeric Antigen ReceptorModified T Cells. Clin Immunol (2014) 155(2):160-75. doi: 10.1016/ j.clim.2014.10.002

40. Tsujimura M, Kusamori K, Nishikawa M. Rapid Regulation of Human Mesenchymal Stem Cell Proliferation Using Inducible Caspase-9 Suicide Gene for Safe Cell-Based Therapy. Int J Mol Sci (2019) 20(22):5759. doi: $10.3390 /$ ijms 20225759

41. Norelli M, Camisa B, Barbiera G, Falcone L, Purevdorj A, Genua M, et al. Monocyte-Derived IL-1 and IL-6 are Differentially Required for CytokineRelease Syndrome and Neurotoxicity Due to CAR T Cells. Nat Med (2018) 24(6):739-48. doi: 10.1038/s41591-018-0036-4

42. Lim WA, June $\mathrm{CH}$. The Principles of Engineering Immune Cells to Treat Cancer. Cell (2017) 168(4):724-40.

43. Jaspers JE, Brentjens RJ. Development of CAR T Cells Designed to Improve Antitumor Efficacy and Safety. Pharmacol Ther (2017) 178(4):83-91.

44. Gill S, Maus MV, Porter DL. Chimeric Antigen Receptor T Cell Therapy: 25 Years in the Making. Blood Rev (2016) 30(3):157-67. doi: 10.1016/ j.blre.2015.10.003

45. Wang QS, Wang Y, Lv HY, Han QW, Fan H, Guo B, et al. Treatment of CD33-Directed Chimeric Antigen Receptor-Modified T Cells in One Patient With Relapsed and Refractory Acute Myeloid Leukemia. Mol Ther: J Am Soc Gene Ther (2015) 23(1):184-91. doi: 10.1038/mt.2014.164
46. Turtle CJ, Maloney DG. Clinical Trials of CD19-Targeted CAR-Modified T Cell Therapy; a Complex and Varied Landscape. Oxfordshire: Taylor \& Francis (2016).

47. Leen AM, Bollard CM, Mendizabal AM, Shpall EJ, Szabolcs P, Antin JH, et al. Multicenter Study of Banked Third-Party Virus-Specific T Cells to Treat Severe Viral Infections After Hematopoietic Stem Cell Transplantation. Blood (2013) 121(26):5113-23. doi: 10.1182/blood-201302-486324

48. Fedorov VD, Sadelain M, Kloss CC. Novel Approaches to Enhance the Specificity and Safety of Engineered T Cells. Cancer J (2014) 20(2):160-5. doi: 10.1097/PPO.0000000000000040

49. Morgan RA, Yang JC, Kitano M, Dudley ME, Laurencot CM, Rosenberg SA. Case Report of a Serious Adverse Event Following the Administration of T Cells Transduced With a Chimeric Antigen Receptor Recognizing ERBB2. Mol Ther: J Am Soc Gene Ther (2010) 18(4):843-51. doi: 10.1038/mt.2010.24

50. Liu X, Jiang S, Fang C, Yang S, Olalere D, Pequignot EC, et al. Affinity-Tuned ErbB2 or EGFR Chimeric Antigen Receptor T Cells Exhibit an Increased Therapeutic Index Against Tumors in Mice. Cancer Res (2015) 75(17):3596607. doi: 10.1158/0008-5472.CAN-15-0159

51. Parkhurst MR, Yang JC, Langan RC, Dudley ME, Nathan DA, Feldman SA, et al. T Cells Targeting Carcinoembryonic Antigen can Mediate Regression of Metastatic Colorectal Cancer But Induce Severe Transient Colitis. Mol Ther: J Am Soc Gene Ther (2011) 19(3):620-6. doi: 10.1038/mt.2010.272

52. Dreno B, Thompson JF, Smithers BM, Santinami M, Jouary T, Gutzmer R, et al. MAGE-A3 Immunotherapeutic as Adjuvant Therapy for Patients With Resected, MAGE-A3-Positive, Stage III Melanoma (DERMA): A DoubleBlind, Randomised, Placebo-Controlled, Phase 3 Trial. Lancet Oncol (2018) 19(7):916-29. doi: 10.1016/S1470-2045(18)30254-7

53. Batchu RB, Gruzdyn OV, Moreno-Bost AM, Szmania S, Jayandharan G, Srivastava A, et al. Efficient Lysis of Epithelial Ovarian Cancer Cells by MAGE-A3-Induced Cytotoxic T Lymphocytes Using rAAV-6 Capsid Mutant Vector. Vaccine (2014) 32(8):938-43. doi: 10.1016/j.vaccine.2013. 12.049

54. Chen X, Wang L, Liu J, Huang L, Yang L, Gao Q, et al. Expression and Prognostic Relevance of MAGE-A3 and MAGE-C2 in Non-Small Cell Lung Cancer. Oncol Lett (2017) 13(3):1609-18. doi: 10.3892/ol.2017.5665

55. Yin B, Zeng Y, Liu G, Wang X, Wang P, Song Y. MAGE-A3 is Highly Expressed in a Cancer Stem Cell-Like Side Population of Bladder Cancer Cells. Int J Clin Exp Pathol (2014) 7(6):2934-41.

56. Shantha Kumara HM, Grieco MJ, Caballero OL, Su T, Ahmed A, Ritter E, et al. MAGE-A3 is Highly Expressed in a Subset of Colorectal Cancer Patients. Cancer Immun (2012) 12:16.

57. Ayyoub M, Scarlata CM, Hamai A, Pignon P, Valmori D. Expression of MAGE-A3/6 in Primary Breast Cancer is Associated With Hormone Receptor Negative Status, High Histologic Grade, and Poor Survival. J Immunother (2014) 37(2):73-6. doi: 10.1097/CJI.0000000000000013

58. Vansteenkiste JF, Cho BC, Vanakesa T, De Pas T, Zielinski M, Kim MS, et al. Efficacy of the MAGE-A3 Cancer Immunotherapeutic as Adjuvant Therapy in Patients With Resected MAGE-A3-Positive Non-Small-Cell Lung Cancer (MAGRIT): A Randomised, Double-Blind, Placebo-Controlled, Phase 3 Trial. Lancet Oncol (2016) 17(6):822-35. doi: 10.1016/S1470-2045(16) 00099-1

59. Wei J, Han X, Bo J, Han W. Target Selection for CAR-T Therapy. J Hematol Oncol (2019) 12(1):62. doi: 10.1186/s13045-019-0758-x

60. Theocharides AP, Rongvaux A, Fritsch K, Flavell RA, Manz MG. Humanized Hemato-Lymphoid System Mice. Haematologica (2016) 101 (1):5-19. doi: 10.3324/haematol.2014.115212

61. Jacoby E, Nguyen SM, Fountaine TJ, Welp K, Gryder B, Qin H, et al. CD19 CAR Immune Pressure Induces B-Precursor Acute Lymphoblastic Leukaemia Lineage Switch Exposing Inherent Leukaemic Plasticity. Nat Commun (2016) 7:12320. doi: 10.1038/ncomms 12320

62. Grada Z, Hegde M, Byrd T, Shaffer DR, Ghazi A, Brawley VS, et al. TanCAR: A Novel Bispecific Chimeric Antigen Receptor for Cancer Immunotherapy. Mol Ther Nucleic Acids (2013) 2:e105. doi: 10.1038/mtna.2013.32

63. MacKay M, Afshinnekoo E, Rub J, Hassan C, Khunte M, Baskaran N, et al. The Therapeutic Landscape for Cells Engineered With Chimeric Antigen Receptors. Nat Biotechnol (2020) 38(2):233-44. doi: 10.1038/s41587-019$0329-2$ 
64. Brentjens RJ, Riviere I, Park JH, Davila ML, Wang X, Stefanski J, et al. Safety and Persistence of Adoptively Transferred Autologous CD19-Targeted T Cells in Patients With Relapsed or Chemotherapy Refractory B-Cell Leukemias. Blood (2011) 118(18):4817-28. doi: 10.1182/blood-2011-04-348540

65. Brudno JN, Somerville RP, Shi V, Rose JJ, Halverson DC, Fowler DH, et al. Allogeneic T Cells That Express an Anti-CD19 Chimeric Antigen Receptor Induce Remissions of B-Cell Malignancies That Progress After Allogeneic Hematopoietic Stem-Cell Transplantation Without Causing Graft-VersusHost Disease. J Clin Oncol (2016) 34(10):1112-21. doi: 10.1200/ JCO.2015.64.5929

66. Schuster SJ, Svoboda J, Chong EA, Nasta SD, Mato AR, Anak O, et al. Chimeric Antigen Receptor T Cells in Refractory B-Cell Lymphomas. N Engl J Med (2017) 377(26):2545-54. doi: 10.1056/NEJMoa1708566

67. Grigor EJM, Fergusson D, Kekre N, Montroy J, Atkins H, Seftel MD, et al. Risks and Benefits of Chimeric Antigen Receptor T-Cell (CAR-T) Therapy in Cancer: A Systematic Review and Meta-Analysis. Transfusion Med Rev (2019) 33(2):98-110. doi: 10.1016/j.tmrv.2019.01.005

68. Wang D, Aguilar B, Starr R, Alizadeh D, Brito A, Sarkissian A, et al. Glioblastoma-Targeted CD4+ CAR T Cells Mediate Superior Antitumor Activity. JCI Insight (2018) 3(10):e99048. doi: 10.1172/jci.insight.99048

69. Di Stasi A, De Angelis B, Rooney CM, Zhang L, Mahendravada A, Foster AE, et al. T Lymphocytes Coexpressing CCR4 and a Chimeric Antigen Receptor Targeting CD30 Have Improved Homing and Antitumor Activity in a Hodgkin Tumor Model. Blood (2009) 113(25):6392-402. doi: 10.1182/ blood-2009-03-209650

70. Nicol AJ, Tokuyama H, Mattarollo SR, Hagi T, Suzuki K, Yokokawa K, et al. Clinical Evaluation of Autologous Gamma Delta T Cell-Based Immunotherapy for Metastatic Solid Tumours. Br J Cancer (2011) 105 (6):778-86. doi: 10.1038/bjc.2011.293

71. Bouet-Toussaint F, Cabillic F, Toutirais O, Le Gallo M, Thomas de la Pintière C, Daniel P, et al. V $\gamma 9 \mathrm{v} \delta 2$ T Cell-Mediated Recognition of Human Solid Tumors. Potential for Immunotherapy of Hepatocellular and Colorectal Carcinomas. Cancer Immunol Immunother (2008) 57(4):531-9. doi: 10.1007/s00262-007-0391-3

72. Soares KC, Rucki AA, Wu AA, Olino K, Xiao Q, Chai Y, et al. PD-1/PD-L1 Blockade Together With Vaccine Therapy Facilitates Effector T-Cell Infiltration Into Pancreatic Tumors. J Immunother (2015) 38(1):1-11. doi: $10.1097 /$ cji.0000000000000062

73. Li S, Siriwon N, Zhang X, Yang S, Jin T, He F, et al. Enhanced Cancer Immunotherapy by Chimeric Antigen Receptor-Modified T Cells Engineered to Secrete Checkpoint Inhibitors. Clin Cancer Res: An Off J Am Assoc Cancer Res (2017) 23(22):6982-92. doi: 10.1158/1078-0432.CCR-17-0867

74. Ambroise J, Giard J, Gala JL, Macq B. Identification of Relevant Properties for Epitopes Detection Using a Regression Model. IEEE/ACM Trans Comput Biol Bioinf (2011) 8(6):1700-7. doi: 10.1109/TCBB.2011.77

75. Mahasa KJ, Ouifki R, Eladdadi A, Pillis L. Mathematical Model of TumorImmune Surveillance. J Theor Biol (2016) 404:312-30. doi: 10.1016/ j.jtbi.2016.06.012

76. Shah NN, Fry TJ. Mechanisms of Resistance to CAR T Cell Therapy. Nat Rev Clin Oncol (2019) 16(6):372-85. doi: 10.1038/s41571-019-0184-6

77. Mitchell P. Critics Pan Timid European Response to TeGenero Disaster. Nat Biotechnol (2007) 25(5):485-6. doi: 10.1038/nbt0507-485

78. Bird L. Calming the Cytokine Storm. Nat Rev Immunol (2018) 18(7):417-7. doi: 10.1038/s41577-018-0030-6

79. Hegde M, Mukherjee M, Grada Z, Pignata A, Landi D, Navai SA, et al. Tandem CAR T Cells Targeting HER2 and IL13Ralpha2 Mitigate Tumor Antigen Escape. J Clin Invest (2016) 126(8):3036-52. doi: 10.1172/JCI83416

80. Zhou X, Brenner MK. Improving the Safety of T-Cell Therapies Using an Inducible Caspase-9 Gene. Exp Hematol (2016) 44(11):1013-9. doi: 10.1016/ j.exphem.2016.07.011

81. Straathof KC, Pule MA, Yotnda P, Dotti G, Vanin EF, Brenner MK, et al. An Inducible Caspase 9 Safety Switch for T-Cell Therapy. Blood (2005) 105 (11):4247-54. doi: 10.1182/blood-2004-11-4564

82. Di Stasi A, Tey SK, Dotti G, Fujita Y, Kennedy-Nasser A, Martinez C, et al. Inducible Apoptosis as a Safety Switch for Adoptive Cell Therapy. N Engl J Med (2011) 365(18):1673-83. doi: 10.1056/NEJMoa1106152

83. Minagawa K, Jamil MO, Al-Obaidi M, Pereboeva L, Salzman D, Erba HP, et al. In Vitro Pre-Clinical Validation of Suicide Gene Modified Anti-CD33
Redirected Chimeric Antigen Receptor T-Cells for Acute Myeloid Leukemia. PloS One (2016) 11(12):e0166891. doi: 10.1371/journal.pone.0166891

84. Dai X, Mei Y, Cai D, Han W. Standardizing CAR-T Therapy: Getting it Scaled Up. Biotechnol Advances (2019) 37(1):239-45. doi: 10.1016/ j.biotechadv.2018.12.002

85. Dai X, Mei Y, Nie J, Bai Z. Scaling Up the Manufacturing Process of Adoptive T Cell Immunotherapy. Biotechnol J (2019) 14(4):e1800239. doi: 10.1002/biot.201800239

86. Miller V, Lin A, Fridman A. Why Target Immune Cells for Plasma Treatment of Cancer. Plasma Chem Plasma Process (2015) 36:259-68. doi: 10.1007/s11090-015-9676-Z

87. Bauer G, Sersenova D, Graves DB, Machala Z. Dynamics of Singlet OxygenTriggered, RONS-Based Apoptosis Induction After Treatment of Tumor Cells With Cold Atmospheric Plasma or Plasma-Activated Medium. Sci Rep (2019) 9:1393. doi: 10.1038/s41598-019-50329-3

88. Schneider C, Gebhardt L, Arndt S, Karrer S, Zimmermann JL, Fischer MJM, et al. Acidification is an Essential Process of Cold Atmospheric Plasma and Promotes the Anti-Cancer Effect on Malignant Melanoma Cells. Cancers (Basel) (2019) 11(5):671. doi: 10.3390/cancers11050671

89. Bekeschus S, Freund E, Spadola C, Privat-Maldonado A, Hackbarth C, Bogaerts A, et al. Risk Assessment of Kinpen Plasma Treatment of Four Human Pancreatic Cancer Cell Lines With Respect to Metastasis. Cancers (Basel) (2019) 11(9):1237. doi: 10.3390/cancers11091237

90. Xiang L, Xu X, Zhang S, Cai D, Dai X. Cold Atmospheric Plasma Conveys Selectivity on Triple Negative Breast Cancer Cells Both In Vitro and In Vivo. Free Radic Biol Med (2018) 124:205-13. doi: 10.1016/j.freeradbiomed.2018.06.001

91. Köritzer J, Boxhammer V, Schafer A, Shimizu T, Klampfl TG, Li YF, et al. Restoration of Sensitivity in Chemo-Resistant Glioma Cells by Cold Atmospheric Plasma [Research Support, Non-U. S Gov't] PloS One (2013) 8(5):e64498. doi: 10.1371/journal.pone.0064498

92. Xu D, Luo X, Xu Y, Cui Q, Yang Y, Liu D, et al. The Effects of Cold Atmospheric Plasma on Cell Adhesion, Differentiation, Migration, Apoptosis and Drug Sensitivity of Multiple Myeloma. Biochem Biophys Res Commun (2016) 473(4):1125-32. doi: 10.1016/j.bbrc.2016.04.027

93. Van Loenhout J, Flieswasser T, Freire Boullosa L, De Waele J, Van Audenaerde J, Marcq E, et al. Cold Atmospheric Plasma-Treated PBS Eliminates Immunosuppressive Pancreatic Stellate Cells and Induces Immunogenic Cell Death of Pancreatic Cancer Cells. Cancers (Basel) (2019) 11(10):1597. doi: 10.3390/cancers11101597

94. Bekeschus S, Clemen R, Metelmann HR. Potentiating Anti-Tumor Immunity With Physical Plasma. Clin Plasma Med (2018) 12:17-22. doi: 10.1016/j.cpme.2018.10.001

95. Lin A, Truong B, Pappas A, Kirifides L, Oubarri A, Chen S, et al. Uniform Nanosecond Pulsed Dielectric Barrier Discharge Plasma Enhances AntiTumor Effects by Induction of Immunogenic Cell Death in Tumors and Stimulation of Macrophages. Plasma Processes Polymers (2016) 12 (12):1392-9. doi: 10.1002/ppap.201500139

96. Li Y, Liu X, Zhang X, Pan W, Li N, Tang B. Immunogenic Cell Death Inducers for Enhanced Cancer Immunotherapy. Chem Commun (Camb) (2021) 57(91):12087-97. doi: 10.1039/d1cc04604g

97. Lin A, Gorbanev Y, De Backer J, Van Loenhout J, Van Boxem W, Lemiere F, et al. Non-Thermal Plasma as a Unique Delivery System of Short-Lived Reactive Oxygen and Nitrogen Species for Immunogenic Cell Death in Melanoma Cells. Adv Sci (Weinh) (2019) 6(6):1802062. doi: 10.1002/ advs.201802062

98. Lin AG, Xiang B, Merlino DJ, Baybutt TR, Sahu J, Fridman A, et al. NonThermal Plasma Induces Immunogenic Cell Death In Vivo in Murine CT26 Colorectal Tumors. Oncoimmunology (2018) 7(9):e1484978. doi: 10.1080/ 2162402X.2018.1484978

99. Khalili M, Daniels L, Lin A, Krebs FC, Snook AE, Bekeschus S, et al. NonThermal Plasma-Induced Immunogenic Cell Death in Cancer: A Topical Review. J Phys D Appl Phys (2019) 52(42):423001. doi: 10.1088/1361-6463/ ab31c1

100. Lin A, Truong B, Patel S, Kaushik N, Choi EH, Fridman G, et al. Nanosecond-Pulsed DBD Plasma-Generated Reactive Oxygen Species Trigger Immunogenic Cell Death in A549 Lung Carcinoma Cells Through Intracellular Oxidative Stress. Int J Mol Sci (2017) 18(5):966. doi: 10.3390/ ijms 18050966 
101. Van Loenhout J, Freire Boullosa L, Quatannens D, De Waele J, Merlin C, Lambrechts H, et al. Auranofin and Cold Atmospheric Plasma Synergize to Trigger Distinct Cell Death Mechanisms and Immunogenic Responses in Glioblastoma. Cells (2021) 10(11):2936. doi: 10.3390/cells10112936

102. Azzariti A, Iacobazzi RM, Di Fonte R, Porcelli L, Gristina R, Favia P, et al. Plasma-Activated Medium Triggers Cell Death and the Presentation of Immune Activating Danger Signals in Melanoma and Pancreatic Cancer Cells. Sci Rep (2019) 9(1):4099. doi: 10.1038/s41598-019-40637-z

103. Almeida ND, Klein AL, Hogan EA, Terhaar SJ, Kedda J, Uppal P, et al. Cold Atmospheric Plasma as an Adjunct to Immunotherapy for Glioblastoma Multiforme. World Neurosurg (2019) 130:369-76. doi: 10.1016/ j.wneu.2019.06.209

104. Alimohammadi M, Golpur M, Sohbatzadeh F, Hadavi S, Bekeschus S, Niaki $\mathrm{HA}$, et al. Cold Atmospheric Plasma Is a Potent Tool to Improve Chemotherapy in Melanoma In Vitro and In Vivo. Biomolecules (2020) 10 (7):1011. doi: 10.3390/biom10071011

105. Wang C, Li P, Liu L, Pan H, Li H, Cai L, et al. Self-Adjuvanted Nanovaccine for Cancer Immunotherapy: Role of Lysosomal Rupture-Induced ROS in MHC Class I Antigen Presentation. Biomaterials (2016) 79:88-100. doi: 10.1016/j.biomaterials.2015.11.040

106. Daeschlein G, Scholz S, Ahmed R, Majumdar A, von Woedtke T, Haase H, et al. Cold Plasma is Well-Tolerated and Does Not Disturb Skin Barrier or Reduce Skin Moisture. J Dtsch Dermatol Ges (2012) 10(7):509-15. doi: 10.1111/j.1610-0387.2012.07857.x

107. Metelmann HR, Vu TT, Do HT, Le TNB, Hoang THA, Phi TTT, et al. Scar Formation of Laser Skin Lesions After Cold Atmospheric Pressure Plasma (CAP) Treatment: A Clinical Long Term Observation. Clin Plasma Med (2013) 1(1):30-5. doi: 10.1016/j.cpme.2012.12.001

108. Metelmann HR, von Woedtke T, Bussiahn R, Weltmann KD, Rieck M, Khalili R, et al. Experimental Recovery of CO2-Laser Skin Lesions by Plasma Stimulation. Am J Cosmetic Surg (2012) 29(1):52-6. doi: 10.5992/ajcs-d-1100042.1

109. Ulrich C, Kluschke F, Patzelt A, Vandersee S, Czaika VA, Richter H, et al. Clinical Use of Cold Atmospheric Pressure Argon Plasma in Chronic Leg Ulcers: A Pilot Study. J Wound Care (2015) 24(5):196, 198-200, 202-3. doi: 10.12968/jowc.2015.24.5.196
110. Metelmann HR, Nedrelow DS, Seebauer C, Schuster M, Woedtke T, Weltmann KD, et al. Head and Neck Cancer Treatment and Physical Plasma. Clin Plasma Med (2015) 3:17-23. doi: 10.1016/j.cpme.2015.02.001

111. Kulaga EM, Jacofsky DJ, McDonnell C, Jacofsky MC. The Use of an Atmospheric Pressure Plasma Jet to Inhibit Common Wound-Related Pathogenic Strains of Bacteria. Plasma Med (2016) 6(1):1-12. doi: 10.1615/ PlasmaMed.2016015851

112. Ishaq M, Zhao JH, Kumar S, Evans MDM, Ostrikov K. AtmosphericPressure Plasma- and TRAIL-Induced Apoptosis in TRAIL-Resistant Colorectal Cancer Cells. Plasma Process Polym (2015) 12(6):574-82. doi: 10.1002/ppap.201400207

113. Ruella M, Xu J, Barrett DM, Fraietta JA, Reich TJ, Ambrose DE, et al. Induction of Resistance to Chimeric Antigen Receptor T Cell Therapy by Transduction of a Single Leukemic B Cell. Nat Med (2018) 24(10):1499-503. doi: 10.1038/s41591-018-0201-9

Conflict of Interest: XD was employed by CAPsoul Biotechnology Company, Ltd, Beijing, China.

The remaining authors declare that the research was conducted in the absence of any commercial or financial relationships that could be construed as a potential conflict of interest.

Publisher's Note: All claims expressed in this article are solely those of the authors and do not necessarily represent those of their affiliated organizations, or those of the publisher, the editors and the reviewers. Any product that may be evaluated in this article, or claim that may be made by its manufacturer, is not guaranteed or endorsed by the publisher.

Copyright (c) 2022 Dai, Li, Chen and Ostrikov. This is an open-access article distributed under the terms of the Creative Commons Attribution License (CC BY). The use, distribution or reproduction in other forums is permitted, provided the original author(s) and the copyright owner(s) are credited and that the original publication in this journal is cited, in accordance with accepted academic practice. No use, distribution or reproduction is permitted which does not comply with these terms. 